\title{
In vivo lung perfusion rehabilitates sepsis-induced lung injury
}

\author{
J. Hunter Mehaffey, MD, MSc, ${ }^{a}$ Eric J. Charles, MD, ${ }^{a}$ Sarah Schubert, MD, ${ }^{a}$ Morgan Salmon, PhD, ${ }^{a}$ \\ Ashish K. Sharma, MBBS, PhD, ${ }^{\mathrm{a}}$ Dustin Money, RRT-ACCS, ${ }^{\mathrm{a}}$ Mark H. Stoler, MD, ${ }^{\mathrm{b}}$ \\ Victor E. Laubach, $\mathrm{PhD},{ }^{\mathrm{a}}$ Curtis G. Tribble, MD, ${ }^{\mathrm{a}}$ Mark E. Roeser, $\mathrm{MD},{ }^{\mathrm{a}}$ and Irving L. Kron, $\mathrm{MD}^{\mathrm{a}}$
}

\section{ABSTRACT}

Background: Sepsis is the leading cause of lung injury in adults and can lead to acute respiratory distress syndrome (ARDS). Using a novel technique of isolated in vivo lung perfusion (IVLP), we hypothesized that normothermic IVLP will improve oxygenation and compliance in a porcine model of sepsis-induced lung injury.

Methods: Mature adult swine $(\mathrm{n}=8)$ were administered lipopolysaccharide (LPS; $50 \mu \mathrm{g} / \mathrm{kg}$ over 2 hours) via the external jugular vein, followed by sternotomy and central extracorporeal membrane oxygenation (ECMO) cannulation (right atrium to ascending aorta). The left pulmonary artery (inflow) and left superior and inferior pulmonary veins (outflow) were dissected out and cannulated to deliver isolated perfusion to the left lung. After 4 hours of normothermic IVLP with Steen solution, the left lung then underwent 4 hours of reperfusion after IVLP decannulation. Airway pressures and lung-specific pulmonary vein blood gases from the right lung (LPS control) and left lung (LPS + IVLP) of the same animal were compared.

Results: All animals demonstrated a significant reduction in the ratio of partial pressure of oxygen in arterial blood $\left(\mathrm{PaO}_{2}\right)$ /fraction of inspired oxygen $\left(\mathrm{FiO}_{2}\right)$ (P/F ratio) and total lung compliance at 2 hours after the start of LPS infusion (mean, $469 \pm 19.7 \mathrm{~mm} \mathrm{Hg}$ vs $222.2 \pm 21.4 \mathrm{~mm} \mathrm{Hg} ; P<.0001$ ). After reperfusion, 6 animals (75\%) exhibited improved lung function, allowing for ECMO decannulation. Lung-specific oxygenation was superior in the left lung after 4 hours of reperfusion (mean, $310.5 \pm 54.7 \mathrm{~mm} \mathrm{Hg}$ vs $201.1 \pm 21.7 \mathrm{~mm} \mathrm{Hg} ; P=.01$ ) Similarly, total lung compliance improved after IVLP of the left lung. The lung wet weight to dry weight ratio demonstrated reduced edema in rehabilitated left lungs (mean, $6.5 \pm 0.3$ vs $7.5 \pm 0.4 ; P=.04$ ).

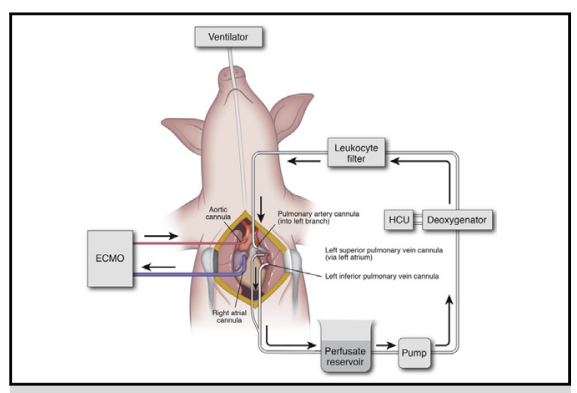

Surgical technique for in vivo lung perfusion cannulation and perfusion.

\section{Central Message}

IVLP can successfully rehabilitate LPSinduced lung injury with improved oxygenation compared to ECMO support alone in a preclinical porcine model.

\section{Perspective}

When translated into a percutaneous platform, in vivo lung perfusion may provide a reliable means to rehabilitate various types of acute lung injury in patients on ECMO to reduce the morbidity and mortality in ARDS.

See Editorial Commentary page 449.

See Editorial page 438.

Conclusions: IVLP successfully rehabilitated LPS-injured lungs compared to ECMO support alone in this preclinical porcine model. (J Thorac Cardiovasc Surg 2018;155:440-8)

From the Departments of ${ }^{\mathrm{a}}$ Surgery and ${ }^{\mathrm{b}}$ Pathology, University of Virginia, Charlottesville, Va.

The research reported in this paper was supported by the National Heart, Lung, and Blood Institute (Grants T32 HL007849, UM1 HL088925, and R01 HL119218). The content is solely the responsibility of the authors and does not necessarily represent the official views of the National Institutes of Health.

Read at the 97th Annual Meeting of The American Association for Thoracic Surgery, Boston, Massachusetts, April 29-May 3, 2017.

Received for publication March 13, 2017; revisions received July 31, 2017; accepted for publication Aug 12, 2017; available ahead of print Oct 18, 2017.

Address for reprints: Irving L. Kron, MD, Department of Surgery, University of Virginia, PO Box 800679, Charlottesville, VA 22908 (E-mail: ilk@virginia.edu).

$0022-5223 / \$ 36.00$

Copyright (c) 2017 by The American Association for Thoracic Surgery

https://doi.org/10.1016/j.jtcvs.2017.08.124
Acute respiratory distress syndrome (ARDS) represents the final devastating result of acute lung injury. This condition has deleterious long-term effects on patients' quality of life and carries significant mortality. ${ }^{1-3}$ Infection and circulatory shock are the predominant etiologies of

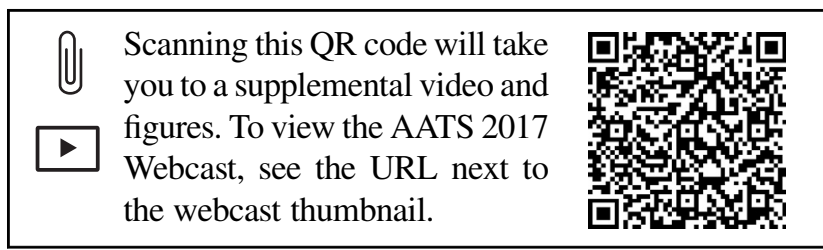




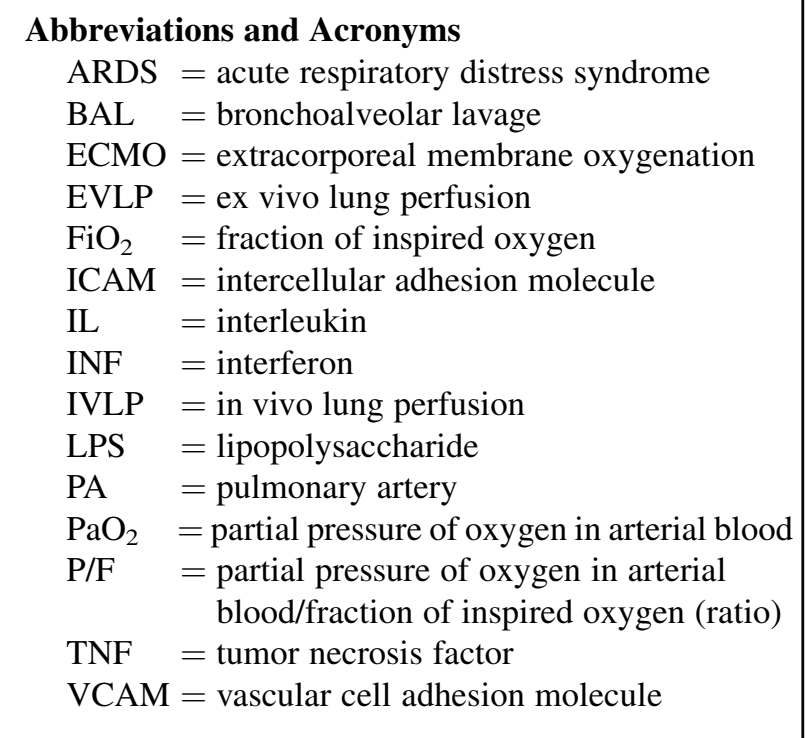

ARDS ${ }^{2,4}$ Extracorporeal membrane oxygenation (ECMO) and protective ventilation strategies are the current standards of care, yet they provide only passive support for innate mechanisms of healing that occur over an often-protracted time course. ${ }^{1,2,5}$ Current forms of pharmacotherapy are extremely limited. Data in support of early corticosteroid use are inconclusive, and administration beyond 14 days is contraindicated. ${ }^{6-8}$ Early treatment with a 48-hour infusion of the neuromuscular blocking agent cisatracurium has been shown to reduce mortality, but has no effect on the duration of mechanical ventilator support. ${ }^{9-11}$ At present, there are no available methods to treat and rapidly rehabilitate lungs affected by ARDS. It has become increasingly apparent that a technological breakthrough is needed to reduce the significant mortality associated with this grave disease.

Recently, ex vivo lung perfusion (EVLP) has demonstrated clinical utility as a platform for assessing donor lungs before transplantation. ${ }^{12}$ Work in our laboratory has shown that EVLP also may provide a useful therapeutic platform for the rehabilitation of injured lungs. ${ }^{13-15}$ This therapy involves placement of cannulas in the pulmonary artery (PA) (inflow) and the left atrium (outflow) for perfusion and an endotracheal tube into the trachea to ventilate the lungs after excision from a donor. The EVLP circuit design is modified from clinical cardiopulmonary bypass and is used for the ex vivo perfusion of lungs. The perfusion circuit includes a membrane deoxygenator that enables evaluation of the oxygenation capacity of the donor lungs. ${ }^{12,16}$ The use of Steen solution (XVIVO Perfusion, Englewood, Colo), a physiological solution consisting of albumin, dextran, and electrolytes supplemented with steroids, antibiotics, and heparin, in EVLP can reduce lung edema, provide free radical scavenging, and ameliorate harmful inflammation and endothelial damage. Steen solution provides an ideal platform for targeted drug, cellular, or gene therapy during EVLP for further improvement in lung recovery. The EVLP circuit also includes a leukocyte-reducing filter, which decreases the burden of circulating inflammatory cells. Finally, a critical principle of EVLP is the maintenance of physiological back-pressure $(+1$ to $5 \mathrm{~mm} \mathrm{Hg})$ on the pulmonary venous drainage to reduce cavitation and vascular injury. ${ }^{16}$ This technology has been taken one step further for isolated lung perfusion in vivo, although it has never been used with rehabilitative intent. ${ }^{17-19}$; Circulatory shock secondary to sepsis is the leading cause of ARDS. Using a porcine model of ARDS induced by endotoxin-mediated lung injury, we sought to test the rehabilitative potential of a novel strategy of isolated left lung in vivo lung perfusion (IVLP) therapy. This previously validated model of sepsis-induced ARDS using systemic lipopolysaccharide (LPS) produces a dose-dependent reduction in oxygenation and lung compliance. ${ }^{20,21} \mathrm{We}$ previously demonstrated a decrease in the ratio of the partial pressure of oxygen in arterial blood $\left(\mathrm{PaO}_{2}\right)$ to the fraction of inspired oxygen $\left(\mathrm{FiO}_{2}\right)(\mathrm{P} / \mathrm{F}$ ratio $)$ and a reduction of dynamic compliance over 4 hours of EVLP. ${ }^{22}$ In the present study, we hypothesized that isolated left lung perfusion via IVLP would result in attenuation of lung injury with reduced inflammation and edema compared with lungs that received ECMO support only.

\section{METHODS}

\section{Animals and Study Groups}

The University of Virginia's Animal Care and Use Committee approved this study and ensured that all procedures were performed in compliance with the National Institutes of Health's 1996 Guide for the Care and Use of Laboratory Animals. Eight farm-raised swine of both sexes (weight, $45-50 \mathrm{~kg}$ ) were used for this study. In each animal, after induction of general anesthesia, a right carotid artery catheter was placed for blood pressure monitoring, a left jugular vein catheter was placed for vascular access, and a Swan-Ganz catheter was placed to monitor cardiac function and blood flow. The animal remained anesthetized with pentobarbital infusion for the duration of the experiment. Conventional ventilation was used with a tidal volume of $8 \mathrm{~mL} / \mathrm{kg}$, a respiratory rate of 12 to 16 breaths/minute, a positive end-expiratory pressure of $5 \mathrm{~mm} \mathrm{Hg}$, and an $\mathrm{FiO}_{2}$ of 0.40 . Systemic arterial blood gases and lung compliance were measured every $30 \mathrm{mi}-$ nutes for the duration of the experiment to assess lung function and performance.

\section{Lung Injury Protocol}

If baseline arterial blood gas and lung compliance measurements demonstrated no intrinsic lung injury, $50 \mu \mathrm{g} / \mathrm{kg}$ of LPS (from Escherichia coli 0127; B8, Sigma-Aldrich, St Louis, Mo) was infused over a 2-hour period to induce lung injury. Then lidocaine $(50 \mathrm{mg})$ was administered, followed by a midline sternotomy and incision of the pericardium. If arterial blood gas and lung compliance measurements confirmed lung injury, then interlocking ascending aortic and running right atrial purse-string sutures were placed with 5-0 Prolene (Ethicon, Somerville, NJ), $100 \mathrm{U} / \mathrm{kg}$ of intravenous heparin (Hospira, Lake Forest, Ill) was administered, and an 18F Bio-Medicus arterial cannula and a 


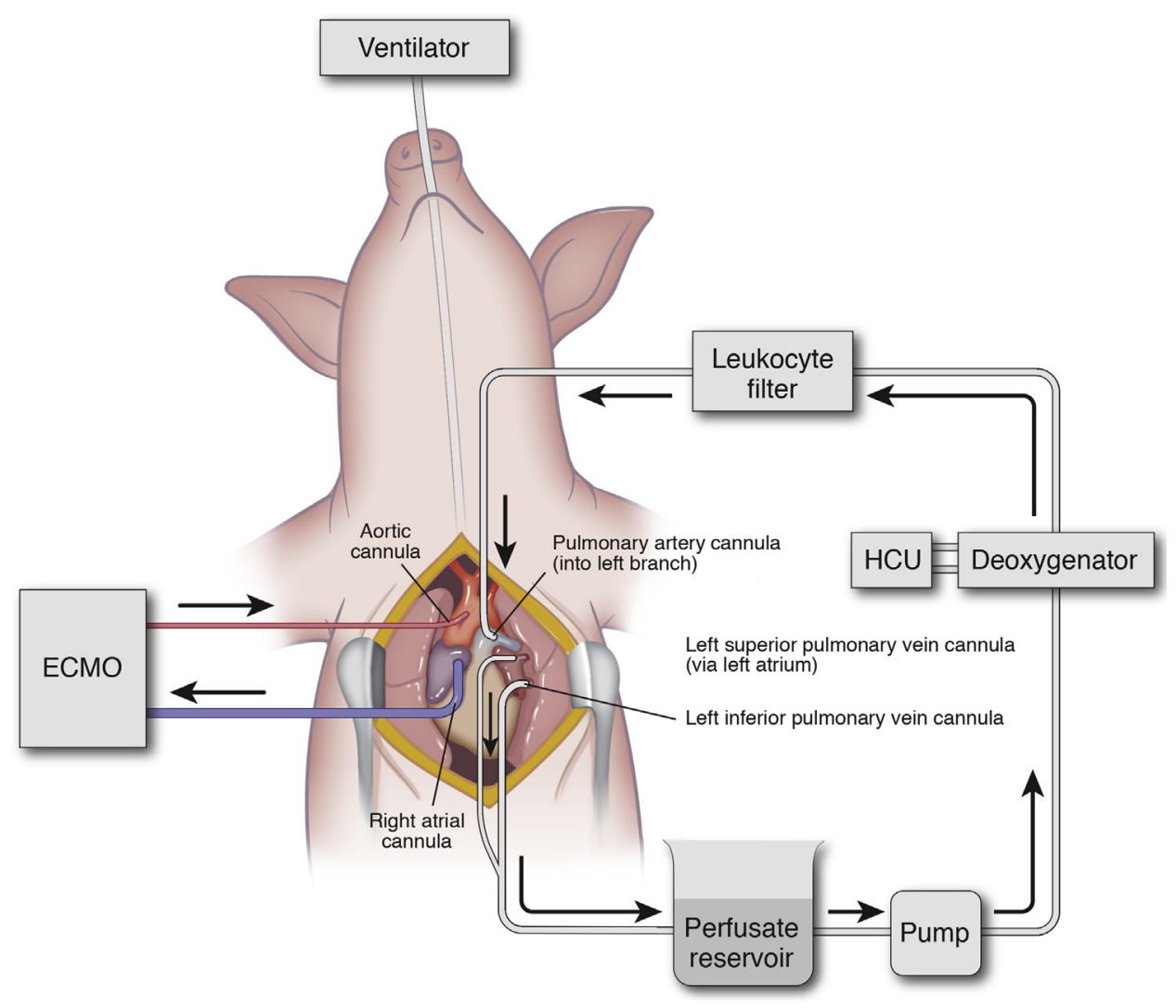

FIGURE 1. Surgical technique for porcine in vivo lung perfusion. ECMO, Extracorporeal membrane oxygenation; $H C U$, heating-cooling unit.

28F Bio-Medicus dual-stage venous cannula (Medtronic, Minneapolis, Minn) were placed for central veno-arterial ECMO. After deairing, the circuit was completed with an Affinity membrane oxygenator and centrifugal pump (Medtronic).

ECMO was initiated with a target mean arterial pressure of $65 \mathrm{~mm} \mathrm{Hg}$. Ventilation was continued at lung-protective settings (tidal volume, $6 \mathrm{~mL} /$ $\mathrm{kg}$; respiratory rate, 8 breaths/minute; positive end-expiratory pressure, $5 \mathrm{~mm} \mathrm{Hg} ; \mathrm{FiO}_{2}, 0.21$ ). The circuit was managed by a certified perfusion specialist following specific criteria for goal-directed resuscitation to maintain a mean arterial pressure of $>65 \mathrm{~mm} \mathrm{Hg}$, including fluid boluses with normal saline and the addition of epinephrine and norepinephrine. Systemic arterial blood gas values were measured every 30 minutes to titrate oxygen delivery, and sodium bicarbonate was given for metabolic acidosis, marked by $\mathrm{pH}<7.30$. Hourly activated clotting time was measured, and heparin was administered to maintain this value between 250 and 350 seconds.

\section{In Vivo Lung Perfusion}

After initiation of ECMO support, perfusion to the left lung was isolated (Figure 1 and Video 1). The left superior and inferior pulmonary veins and left PA were dissected circumferentially and snared with 0-Silk sutures and Rommel tourniquets. Purse string sutures were placed in the left PA, the left inferior pulmonary vein, and the left atrium (for the superior vein) with a 5-0 Prolene to allow for cannulation. Arterial catheters (14F) were used for the PA and superior vein, and a $14 \mathrm{~F}$ right-angle cannula was used for the inferior vein. After placement of each cannula, a Rommel tourniquet was used to tighten the purse string suture, and the snare suture was then cinched tight around the distal tip of the catheter to isolate each vessel. To prevent lung injury from outflow obstruction, the PA was cannulated and isolated first, followed by the inferior vein and then the superior vein.

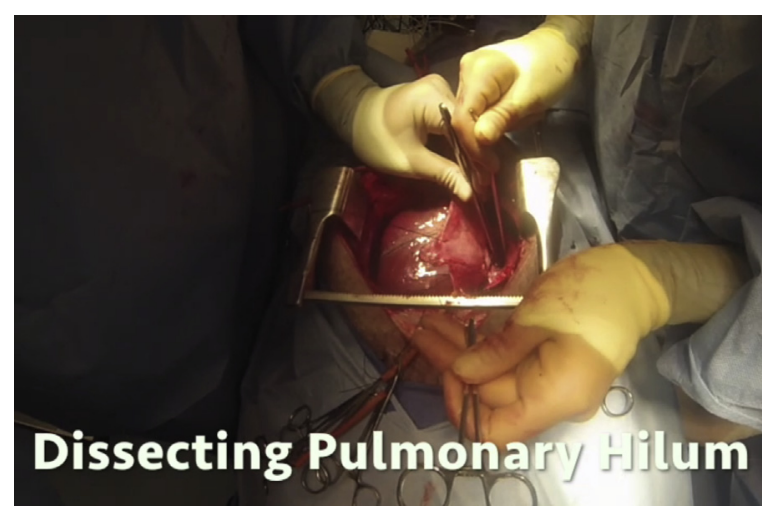

VIDEO 1. University of Virginia porcine in vivo lung perfusion cannulation procedure: dissecting pulmonary hilum (00:04); left PA purse-string (00:22); left atrial purse-string (00:35); central ECMO cannulation (01:00); dissection of the left pulmonary veins (01:15); left PA cannulation (01:30); left inferior pulmonary vein cannulation (01:50); left superior pulmonary vein cannulation (02:35); connecting IVLP (02:55); IVLP diagram (03:15). Video available at: http://www.jtcvsonline.org/article/S00225223(17)31899-8/fulltext. 
After the system was deaired, the circuit was completed with an Affinity Pixie oxygenation system (Medtronic), to deoxygenate the perfusate, and a centrifugal pump (Medtronic). Outflow was opened, followed immediately by gentle inflow, which was gradually increased to up to $8 \%$ of cardiac output with Steen solution supplemented with cefazolin (500 mg; APP Pharmaceuticals, Schaumburg, Ill), methylprednisolone (500 mg; Pfizer, New York, NY), and heparin (5000 IU) at $37.5^{\circ} \mathrm{C}$. Isolated left lung perfusion (IVLP) was maintained for 4 hours while the animal was receiving on central ECMO support. Inflow (left PA) and outflow (left pulmonary vein) pressures were measured, and outflow pressure was maintained between 0 and $-5 \mathrm{~mm} \mathrm{Hg}$. Lung oxygenation capacity was calculated hourly. For the right lung, the difference between the right pulmonary vein $\mathrm{PaO}_{2}$ and right PA sample from the Swan-Ganz catheter was used. The oxygenation capacity of the left lung was calculated as the difference between IVLP circuit outflow (left pulmonary veins) and IVLP circuit inflow (left PA). Serum albumin levels were measured in the animal, in the perfusate before initiation of IVLP, and in the animal after IVLP to determine the extent of mixing between the circuits through the left bronchial arteries and left pulmonary veins. We found decreased serum albumin levels during IVLP despite very high levels of albumin in the perfusate, indicating no mixing from the IVLP circuit into systemic circulation (Figure E1). After 2 hours, the IVLP perfusate (Steen solution) was exchanged for fresh Steen solution. After 4 hours of IVLP perfusion, the left lung was reperfused via the systemic circulation, and the IVLP cannulas were removed. Right pulmonary vein- and left pulmonary vein- specific arterial blood gas values were measured hourly to assess the performance of each lung independently. Over the final 4 hours of in vivo reperfusion, attempts were made to wean the animal from ECMO support, and if successful, the animal was decannulated from central veno-arterial ECMO. At the end of the experiment, tissue and blood samples were collected, and the animal was euthanized.

\section{Histopathology}

From the left lung and right lung, 3 fresh tissue samples (1 upper lobe, 2 lower lobe) were obtained and weighed. A vacuum oven was used to desiccate the tissues at $55^{\circ} \mathrm{C}$. Wet-to-dry weight ratios were calculated using separate tissue samples and averaged per lung to assess overall pulmonary edema accumulation.

After fresh tissue samples were obtained, the lungs were fixed via intratracheal instillation of $10 \%$ buffered formalin and then stored submerged overnight at $4^{\circ} \mathrm{C}$. Following overnight fixation, peripheral lung tissue samples (4 per lung) were obtained, embedded in paraffin, and sectioned. One slide per sample was stained with hematoxylin and eosin. A masked pathologist assessed the hematoxylin and eosin-stained slides for the presence of lung injury. Each slide was scored on a standard scale based on infiltration of polymorphonuclear cells per $40 \times$ high-power field (0-3), alveolar edema $(0-3)$, and interstitial inflammation $(0-3)$, as described previously. ${ }^{23,24}$

\section{Expression of Biomarkers of Injury and Inflammation}

Fresh tissue samples were flash-frozen in liquid nitrogen and stored at $-80^{\circ} \mathrm{C}$. After homogenization using a FastPrep-24 instrument with Lysing Matrix D tubes (MP Biomedicals, Santa Ana, Calif), the total protein concentration in the supernatant was determined with the bicinchoninic acid protein assay (Pierce, Rockford, Ill). Bronchoalveolar lavage (BAL) of the upper lobe of the lung was also performed, and the BAL fluid obtained was centrifuged and stored at $-80^{\circ} \mathrm{C}$. In addition, isolated left lung perfusate samples were collected 2 hours after the initiation of IVLP, centrifuged, and stored at $-80^{\circ} \mathrm{C}$. A multiplex enzyme-linked immunosorbent assay (EMD Millipore, Billerica, Mass) was used to measure cytokine levels in homogenized tissue supernatant (normalized to total protein) or BAL fluid.

Expression of vascular cellular adhesion molecule 1 (VCAM-1) and intracellular adhesion molecule 1 (ICAM-1) in lung tissue was assessed by Western blot analysis. For this analysis, $15 \mu \mathrm{g}$ of whole-cell protein extract was electrophoresed in a $12 \%$ Bis-Tris polyacrylamide gel, then transferred to a nitrocellulose membrane. The membranes were blocked in Tris-buffered saline for 1 hour and in Tween 20 with 5\% nonfat milk for 1 hour. After blocking, membranes were incubated with antiVCAM-1 monoclonal antibody (1:1000; Abcam, Cambridge, United Kingdom) or anti-ICAM-1 monoclonal antibody (1:1000; Abcam) overnight. After 3 washes, membranes were then incubated in horseradish peroxidase-conjugated secondary antibody, followed by another series of washes. Protein was visualized by autoradiography and then analyzed using Image Analysis software (Bio-Rad, Hercules, Calif). Densities were standardized against $\beta$-actin levels for each sample.

\section{Statistical Analysis}

The Wilcoxon signed-rank paired test for nonparametric data was used to determine statistical significance. To account for repeated measures, a mixed-effects linear regression model with repeated measures was fit. Prism 7 (GraphPad Software, La Jolla, Calif) and SAS version 9.4 (SAS Institute, Cary, NC) were used to perform statistical calculations. All data are reported as mean \pm standard deviation. A $P$ value $<.05$ was considered to indicate statistical significance.

\section{RESULTS}

\section{In Vivo Lung Perfusion Model}

A total of 8 adult swine underwent the experimental protocol, with significant acute lung injury after infusion of LPS (P/F ratio, $469.0 \pm 60.1$ initially vs $222.2 \pm 60.62$ at 2 hours after LPS infusion; $P<.008$ ) (Figure 2). Of note, there was no difference in oxygenation performance between the right lung and left lung of each animal at baseline and at 2 hours postinjury (Figure E2). All animals were placed on ECMO for respiratory and circulatory support. After isolation of the left pulmonary vasculature, all
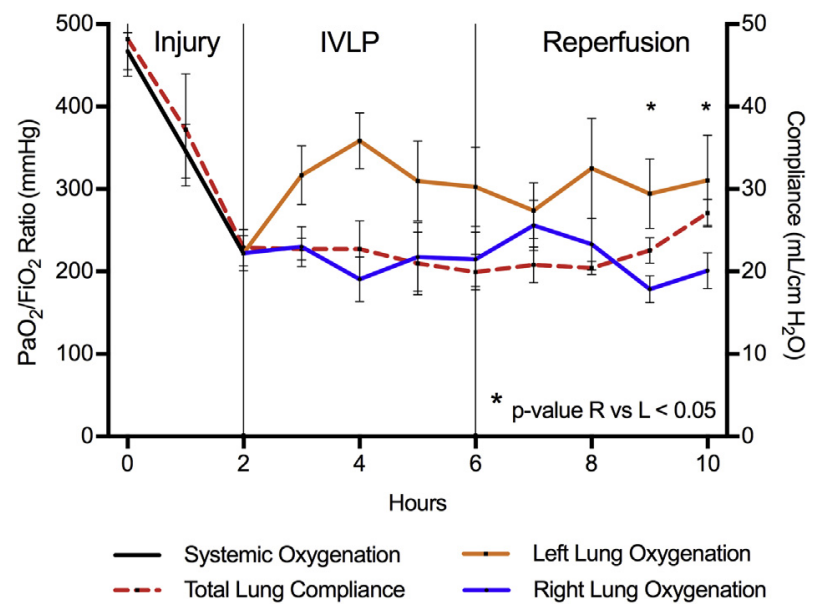

FIGURE 2. Oxygenation (P/F ratio) and total lung compliance. Both systemic oxygenation (black) and total lung compliance (red) dropped precipitously over the 2-hour lung injury with lipopolysaccharide. After isolation and cannulation for in vivo lung perfusion, oxygenation improved significantly in the left lung (orange) compared with the right lung (blue). After decannulation and reperfusion, the left lung continued to improve, as did total lung compliance $(\mathrm{red})$. $* P<.05$ for left lung versus right lung oxygenation. IVLP, In vivo lung perfusion; $\mathrm{PaO}_{2}$, partial pressure of oxygen in arterial blood; $\mathrm{FiO}_{2}$, fraction of inspired oxygen. 


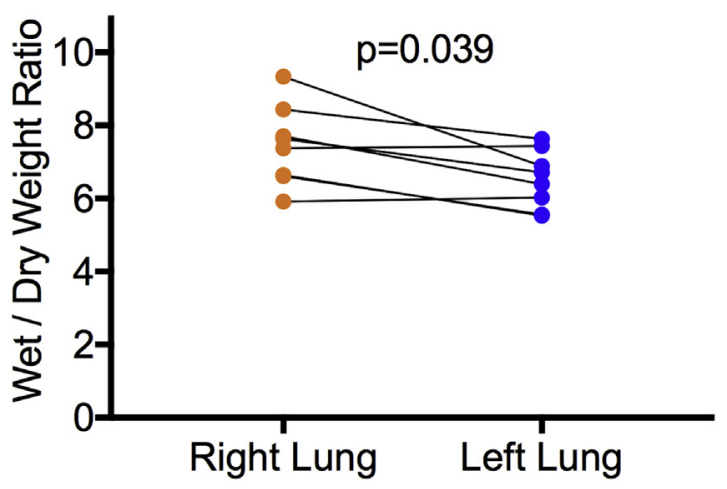

FIGURE 3. Wet weight/dry weight ratio of the left lung compared with the right lung in each animal as a measurement of lung edema.

animals underwent successful IVLP cannulation. Subsequently, left lung oxygenation increased significantly after 2 hours of IVLP (mean P/F ratio, $358.7 \pm 127.6 \mathrm{~mm} \mathrm{Hg}$ in left lung vs $190.8 \pm 110.6 \mathrm{~mm} \mathrm{Hg}$ in right lung; $P=.035)$, and it remained significantly higher after 4 hours of IVLP (mean P/F ratio, $302.7 \pm 135.2 \mathrm{~mm} \mathrm{Hg}$ in left lung vs $214.7 \pm 93.0 \mathrm{~mm} \mathrm{Hg}$ in right lung; $P=.048$ ) (Figure 2). Following IVLP decannulation and 3 hours of reperfusion, the left lung still demonstrated significantly greater oxygenation than the right lung (mean P/F ratio, $294.4 \pm 119.2 \mathrm{~mm}$ $\mathrm{Hg}$ in left lung $178.5 \pm 46.2 \mathrm{~mm} \mathrm{Hg}$ in right lung; $P=.039$ ) (Figure E3, C). Final lung-specific oxygenation at the end of the reperfusion period demonstrated that the left lung remained significantly improved while the right lung

A
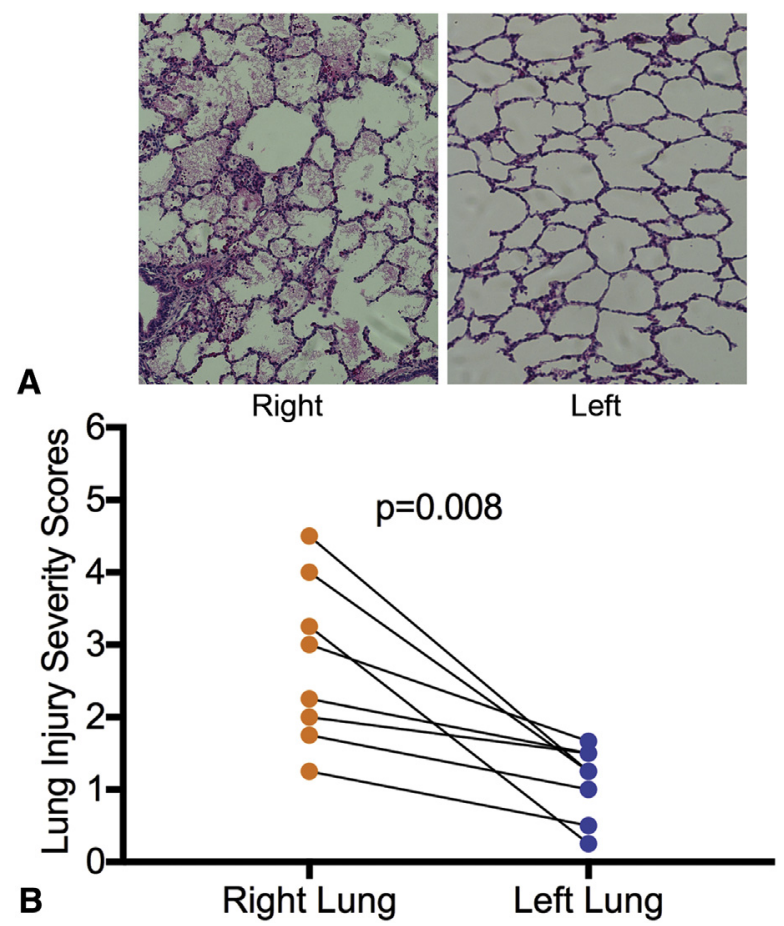

FIGURE 4. A, Hematoxylin and eosin-stained histological micrographs of the left and right lungs of each animal (original magnification, $40 \times$ ). B, Lung injury scores for the left and right lungs of each animal. continued to worsen (mean P/F ratio, $310.5 \pm 154.4 \mathrm{~mm}$ $\mathrm{Hg}$ in left lung vs $201.1 \pm 64.4 \mathrm{~mm} \mathrm{Hg}$ in right lung; $P=.008$ ) (Figure 2 and Figure E3, D). Furthermore, after 4 hours of reperfusion, 6 of the 8 animals $(75 \%)$ showed adequate improvement in respiratory status to allow successful ECMO decannulation. In addition, total lung compliance improved significantly from postinjury to postreperfusion (mean, $22.9 \pm 6.3 \mathrm{~mL} / \mathrm{cmH}_{2} \mathrm{O}$ vs $27.1 \pm 4.7 \mathrm{~mL} / \mathrm{cmH}_{2} \mathrm{O} ; P=.008$ ) (Figure 2 and Figure E2, C). Finally, our mixed-effects linear regression model yielded a mean parameter estimate of $+73.9 \pm 18.9 \mathrm{~mm} \mathrm{Hg}$ for IVLP treatment $(P<.0001)$.

\section{Histopathology}

Measurement of lung wet weight-to-dry weight ratios after reperfusion demonstrated significantly reduced edema in the left lungs compared with the right lungs (mean, $6.5 \pm 0.8$ vs $7.5 \pm 1.1 ; P=.039$ ) (Figure 3). Furthermore, lung histology was noticeably improved and lung injury severity scores were significantly reduced in the left lungs compared with the right lungs (mean, $1.1 \pm 0.5$ vs $2.8 \pm 1.1 ; P=.008$ ) (Figure 4).

\section{Inflammatory Biomarker Analysis}

Expression of the proinflammatory cytokine tumor necrosis factor (TNF)- $\alpha$ was significantly attenuated in the left lung compared with the right lung in both lung tissue homogenate (mean, $0.164 \pm 0.12 \mathrm{pg} / \mathrm{mL}$ in left lung vs $0.163 \pm 0.14 \mathrm{pg} / \mathrm{mL}$ in right lung; $P=.039$ ) and BAL fluid (mean, $0.081 \pm 0.04 \mathrm{pg} / \mathrm{mL}$ in left lung vs $0.165 \pm 0.10 \mathrm{pg} /$ $\mathrm{mL}$ in right lung; $P=.078$ ) (Figure $5, A$ and $B$ ). In addition, expression of the proinflammatory cytokine interferon (IFN)- $\gamma$ was significantly lower in both lung tissue homogenate and BAL from the treated left lung compared with the control right lung (lung tissue, mean $0.093 \pm 0.02 \mathrm{pg} / \mathrm{mL}$ in left lung vs $0.130 \pm 0.03 \mathrm{pg} / \mathrm{mL}$ in right lung, $P=.046$; BAL fluid, mean $0.104 \pm 0.02 \mathrm{pg} / \mathrm{mL}$ in left lung vs $0.138 \pm 0.04 \mathrm{pg} / \mathrm{mL}$ in right lung, $P=.078$ ) (Figure $5, A$ and $B$ ). Expression of the anti-inflammatory cytokine interleukin (IL)-4 was significantly elevated in the left lungs compared with the right lungs (in lung tissue, mean $1.649 \pm 0.48 \mathrm{pg} / \mathrm{mL}$ in left lung vs $1.138 \pm 0.37 \mathrm{pg} / \mathrm{mL}$ in right lung, $P=.039$; in BAL fluid, mean $1.219 \pm 0.59$ $\mathrm{pg} / \mathrm{mL}$ in left lung vs $0.625 \pm 0.45 \mathrm{pg} / \mathrm{mL}$ in right lung, $P=.016$ ) (Figure 6).

Western blot analysis demonstrated a significantly decreased expression ratio of VCAM-1 in the left lungs compared with the right lungs (mean, $0.201 \pm 0.10$ vs $0.117 \pm 0.12 ; P=.0391$ ) (Figure $7, A$ ). Similarly, the ICAM-1 expression ratio was lower in the left lungs, although the difference did not reach statistical significance (mean, $0.377 \pm 0.08$ vs $0.297 \pm 0.16$; $P=.156$ ) (Figure 7, B). 

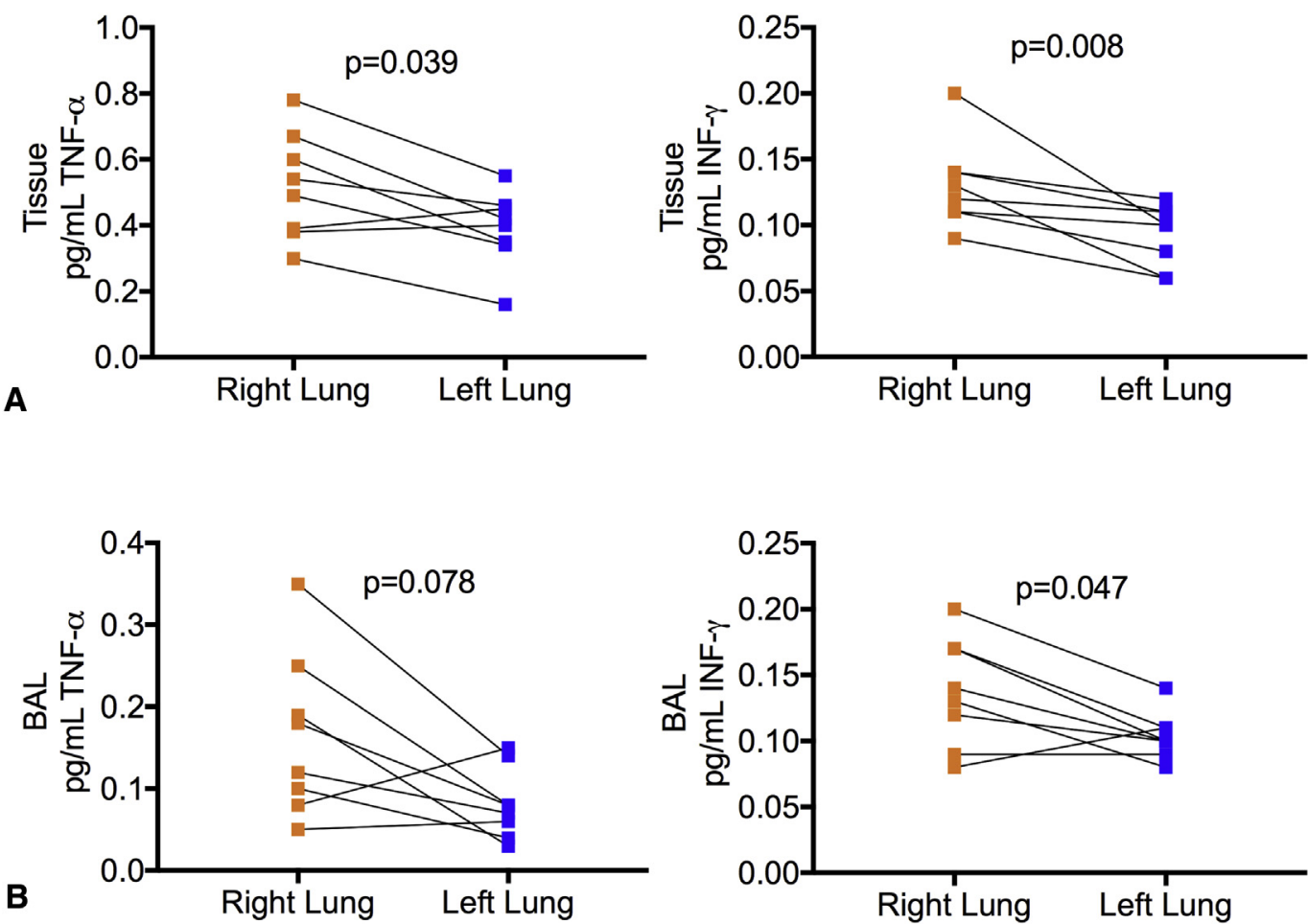

FIGURE 5. A, Proinflammatory cytokine concentrations in tissue of the left and right lungs of each animal. B, Proinflammatory cytokine concentrations in bronchoalveolar lavage fluid samples from the left and right lungs of each animal. $T N F$, Tumor necrosis factor; $I N F$, interferon; $B A L$, bronchoalveolar lavage.

\section{DISCUSSION}

In the present study, IVLP of the left lung resulted in significant rehabilitation of sepsis-induced ARDS over a 10-hour period in a preclinical porcine model. Both lungspecific oxygenation and total lung compliance improved after IVLP therapy, with $75 \%$ of the animals no longer requiring ECMO support. The mechanism responsible for this improved lung function was likely multifactorial, including reduction of pulmonary edema and attenuation of the inflammatory pathways in the treated lung. These data indicate that IVLP therapy with Steen solution reduces the expression of proinflammatory cytokines TNF- $\alpha$ and
INF- $\gamma$ while increasing expression of the antiinflammatory cytokine IL-4. These results correlate with reduced expression of adhesion molecules VCAM-1 and ICAM-1, critical mediators of leukocyte transmigration into lung tissue, after IVLP treatment. This proof-ofconcept study can serve as a launching pad for a novel advanced and rapid surgical approach to treating ARDS, which will require conversion into a percutaneous platform for translation to clinical use.

Steen solution was first described by Steen and colleagues $^{25}$ in 2001 as a physiological acellular perfusate consisting of albumin, dextran, and electrolytes, and was
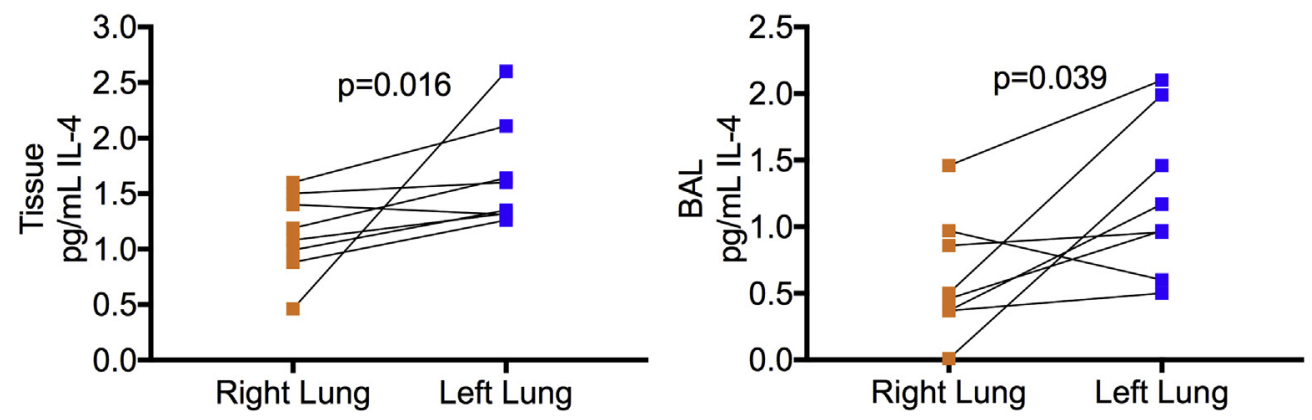

FIGURE 6. Anti-inflammatory cytokine IL-4 concentrations in tissue and bronchoalveolar lavage fluid samples from the left and right lungs of each animal. $I L$, Interleukin; $B A L$, bronchoalveolar lavage. 

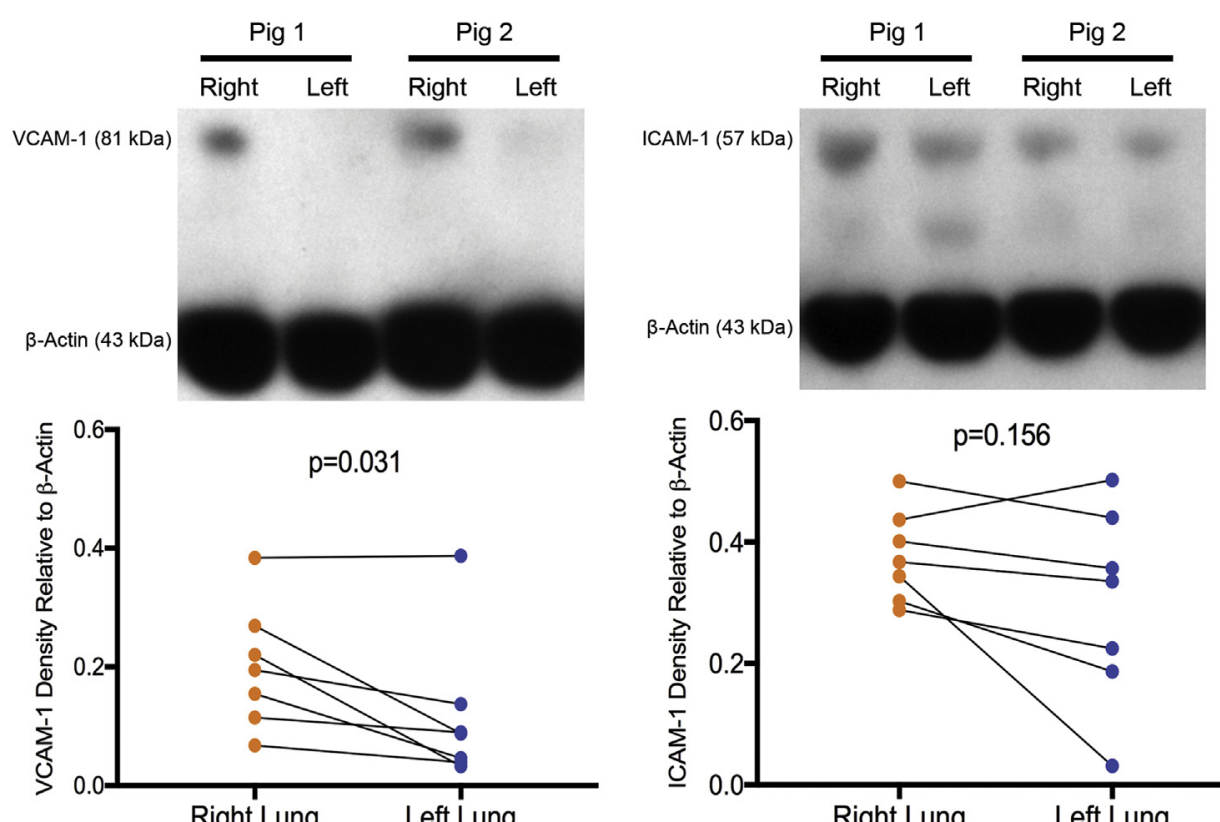

Right Lung Left Lung

A

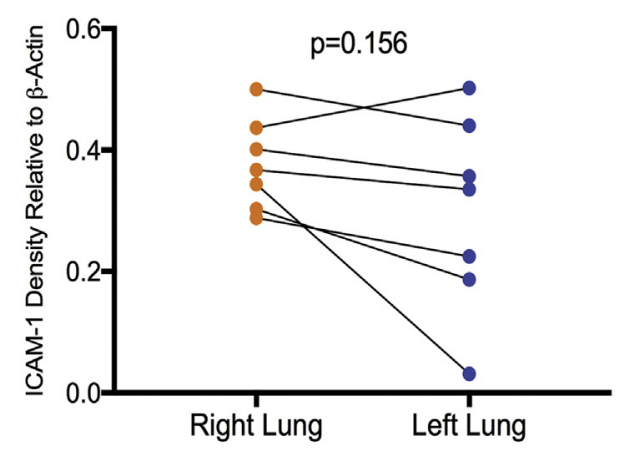

B

FIGURE 7. A, Western blot showing significantly lower VCAM-1 expression in the left lung compared with the right lung of each animal. B, Western blot showing lower ICAM-1 expression in the left lung compared with the right lung of each animal. VCAM, Vascular cell adhesion molecule; ICAM, intercellular adhesion molecule.

subsequently modified by a Toronto group for use in EVLP and lung transplantation. ${ }^{12,26}$ Several groups have demonstrated that perfusion with Steen solution can reduce pulmonary edema in ex vivo perfused lungs. ${ }^{23,27,28}$ Our LPS-induced model of porcine ARDS simulates the increased vascular permeability observed during sepsis. This injury was ameliorated by 4 hours of IVLP perfusion, and our data demonstrate enduring edema reduction even after 4 hours of reperfusion. In this preclinical model, reduced pulmonary edema is a critical mechanism in improved lung function after IVLP therapy.

Sepsis-induced lung injury through the LPS pathway stimulates an inflammatory cascade through activation of Toll-like receptor 4 (TLR-4), leading to activation of neutrophils and macrophages. ${ }^{29}$ Both TNF- $\alpha$ and INF- $\gamma$ are proinflammatory cytokines within this pathway that help amplify the inflammatory response. After 4 hours of IVLP treatment, reduced expression of these cytokines was found in the rehabilitated left lungs compared with the right control lungs despite 4 additional hours of reperfusion. IL-4, a potent immunomodulatory cytokine synthesized and released by Th2 lymphocytes, is known to suppress LPSinduced COX-2 expression in monocytes ${ }^{30,31}$ and also to suppress proinflammatory cytokine production. ${ }^{32}$ Wehrmann and colleagues ${ }^{33}$ recently suggested that IL-4 expression decreases TNF- $\alpha$ production by resident alveolar macrophages, thereby reducing accumulation of M1 macrophages, inflammation, and alveolar-capillary leak. This anti-inflammatory pathway represents another potential mechanism by which IVLP rehabilitates sepsis-induced lung injury via induction of pathways that mediate resolution of injury.

The pathophysiology of sepsis is associated with an aberrant interaction between leukocytes and vascular endothelium involving the up-regulation of expression of cell adhesion molecules, including VCAM- 1 and ICAM- $1 .^{34}$ Endothelial adhesion molecules play critical roles in LPS-induced lung injury, allowing transmigration of inflammatory cells. ${ }^{35}$ This up-regulation of adhesion molecules attracts neutrophils and lymphocytes, further amplifying the inflammatory cascade through release of additional chemoattractants. Thus, we measured the protein expression of VCAM-1 and ICAM-1 in lung tissue as a further indicator of vascular inflammation. In this study, IVLP-treated lungs exhibited significantly reduced VCAM-1 expression compared with untreated lungs, suggesting another mechanism by which IVLP attenuates acute lung injury in this porcine model of sepsis.

Limitations of this study include the complexity of this large animal model, resulting in some variation between animals; however, our comparison of results in the left and right lungs of the same animal minimizes this effect. Nonetheless, although this validated porcine model of sepsisinduced acute lung injury demonstrates a reproducible reduction in lung compliance and oxygenation, it does not directly translate to the chronic nature of sepsis in a critically ill patient with severe ARDS necessitating ECMO. Additional mechanistic studies are needed to discover 
specific signaling pathways that are affected by IVLP, with Steen solution providing attenuation of lung injury. Finally, translation into human studies will require an entirely percutaneous approach to IVLP, which hopefully will ultimately lead to the transformation of ARDS from a longterm condition with high morbidity and mortality to a treatable illness with shorter recovery, lower healthcare-related costs, and increased survival.

In conclusion, 4 hours of IVLP significantly rehabilitated LPS-induced lung injury and attenuated the need for ECMO support in $75 \%$ of animals. Lung injury is ameliorated by IVLP through several mechanisms involving reduced lung edema, reduced proinflammatory cytokine and adhesion molecule levels, and increased anti-inflammatory cytokine levels. In the near future, when translated into a percutaneous platform, IVLP may provide a reliable means to rehabilitate various types of acute lung injury in patients on ECMO, leading to reduced morbidity and mortality in patients with ARDS.

\section{Webcast}

You can watch a Webcast of this AATS meeting presentation by going to: https://aats.blob.core.windows.net/media/ 17AM/2017-05-01/Booth-106/05-01-17_CTTheaterI_Booth106_1335_Mehaffey.mp4.

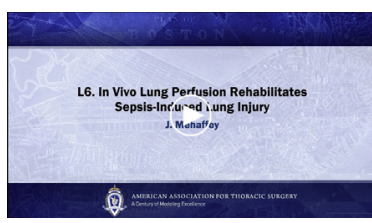

\section{Conflict of Interest Statement}

Authors have nothing to disclose with regard to commercial support.

Special thanks to Tony Herring, Cindy Dodson, and Sheila Hammond for their technical support and continued commitment to the completion of this project.

\section{References}

1. Schmidt M, Zogheib E, Roze H, Repesse X, Lebreton G, Luyt CE, et al. The PRESERVE mortality risk score and analysis of long-term outcomes after extracorporeal membrane oxygenation for severe acute respiratory distress syndrome. Intensive Care Med. 2013;39:1704-13.

2. Tonelli AR, Zein J, Adams J, Ioannidis JP. Effects of interventions on survival in acute respiratory distress syndrome: an umbrella review of 159 published randomized trials and 29 meta-analyses. Intensive Care Med. 2014;40:769-87.

3. Bellani G, Laffey JG, Pham T, Fan E, Brochard L, Esteban A, et al. Epidemiology, patterns of care, and mortality for patients with acute respiratory distress syndrome in intensive care units in 50 countries. JAMA. 2016:315:788-800.

4. Modig J. Adult respiratory distress syndrome: pathogenesis and treatment. Acta Chir Scand. 1986;152:241-9.

5. Windsor AC, Mullen PG, Fowler AA. Acute lung injury: what have we learned from animal models? Am J Med Sci. 1993;306:111-6.

6. Meduri GU, Schwingshackl A, Hermans G. Prolonged glucocorticoid treatment in ARDS: impact on intensive care unit-acquired weakness. Front Pediatr. 2016;4:69.
7. Ortiz-Diaz E, Festic E, Gajic O, Levitt JE. Emerging pharmacological therapies for prevention and early treatment of acute lung injury. Semin Respir Crit Care Med. 2013;34:448-58.

8. Peter JV, John P, Graham PL, Moran JL, George IA, Bersten A. Corticosteroids in the prevention and treatment of acute respiratory distress syndrome (ARDS) in adults: meta-analysis. BMJ. 2008;336:1006-9.

9. Serpa Neto A, Simonis FD, Barbas CS, Biehl M, Determann RM, Elmer J, et al. Association between tidal volume size, duration of ventilation, and sedation needs in patients without acute respiratory distress syndrome: an individual patient data meta-analysis. Intensive Care Med. 2014;40:950-7.

10. Alhazzani W, Alshahrani M, Jaeschke R, Forel JM, Papazian L, Sevransky J, et al. Neuromuscular blocking agents in acute respiratory distress syndrome: a systematic review and meta-analysis of randomized controlled trials. Crit Care. 2013;17:R43.

11. Bosma KJ, Taneja R, Lewis JF. Pharmacotherapy for prevention and treatment of acute respiratory distress syndrome: current and experimental approaches. Drugs. 2010;70:1255-82.

12. Cypel M, Yeung JC, Hirayama S, Rubacha M, Fischer S, Anraku M, et al. Technique for prolonged normothermic ex vivo lung perfusion. J Heart Lung Transplant. 2008;27:1319-25.

13. Mulloy DP, Sharma AK, Fernandez LG, Zhao Y, Lau CL, Kron IL, et al. Adenosine A3 receptor activation attenuates lung ischemia-reperfusion injury. Ann Thorac Surg. 2013;95:1762-7.

14. Stone ML, Sharma AK, Zhao Y, Charles EJ, Huerter ME, Johnston WF, et al Sphingosine-1-phosphate receptor 1 agonism attenuates lung ischemiareperfusion injury. Am J Physiol Lung Cell Mol Physiol. 2015;308:L1245-52.

15. LaPar DJ, Laubach VE, Emaminia A, Crosby IK, Hajzus VA, Sharma AK, et al. Pretreatment strategy with adenosine A2A receptor agonist attenuates reperfusion injury in a preclinical porcine lung transplantation model. J Thorac Cardiovasc Surg. 2011;142:887-94.

16. Mulloy DP, Stone ML, Crosby IK, LaPar DJ, Sharma AK, Webb DV, et al Ex vivo rehabilitation of non-heart-beating donor lungs in preclinical porcine model: delayed perfusion results in superior lung function. J Thorac Cardiovasc Surg. 2012;144:1208-15.

17. Cypel M, Keshavjee S. Isolated lung perfusion. Front Biosci (Elite Ed). 2012;4 2226-32.

18. dos Santos PR, Iskender I, Machuca T, Hwang D, dePerrot M, Liu M, et al. Modified in vivo lung perfusion allows for prolonged perfusion without acute lung injury. J Thorac Cardiovasc Surg. 2014;147:774-81; discussion 781-2.

19. dos Santos PR, Sakamoto J, Chen M, Linacre V, Arce C, Liu M, et al. Modified in vivo lung perfusion for local chemotherapy: a preclinical study with doxorubicin. Ann Thorac Surg. 2016;101:2132-40.

20. Modig J, Borg T. High-dose methylprednisolone in a porcine model of ARDS induced by endotoxemia. Acta Chir Scand Suppl. 1985;526:94-103.

21. Wang HM, Bodenstein M, Markstaller K. Overview of the pathology of three widely used animal models of acute lung injury. Eur Surg Res. 2008;40:305-16.

22. Mehaffey JH, Charles EJ, Sharma AK, Salmon M, Money D, Schubert S, et al Ex vivo lung perfusion rehabilitates sepsis-induced lung injury. Ann Thorac Surg. 2017;103:1723-9.

23. Mehaffey JH, Charles EJ, Sharma AK, Money DT, Zhao Y, Stoler MH, et al Airway pressure release ventilation during ex vivo lung perfusion attenuates injury. J Thorac Cardiovasc Surg. 2017;153:197-204.

24. Charles EJ, Huerter ME, Wagner CE, Sharma AK, Zhao Y, Stoler MH, et al Donation after circulatory death lungs transplantable up to six hours after ex vivo lung perfusion. Ann Thorac Surg. 2016;102:1845-53.

25. Steen S, Liao Q, Wierup PN, Bolys R, Pierre L, Sjöberg T. Transplantation of lungs from non-heart-beating donors after functional assessment ex vivo. Ann Thorac Surg. 2003;76:244-52; discussion 252.

26. Cypel M, Rubacha M, Yeung J, Hirayama S, Torbicki K, Madonik M, et al Normothermic ex vivo perfusion prevents lung injury compared to extended cold preservation for transplantation. Am J Transplant. 2009;9:2262-9.

27. Fernandes LM, Mariani AW, Medeiros IL, Samano MN, Abdalla LG, Correia AT, et al. Alternative solution for ex vivo lung perfusion, experimental study on donated human lungs non-accepted for transplantation. Acta Cir Bras. 2015; 30:359-65.

28. Yeung JC, Cypel M, Waddell TK, van Raemdonck D, Keshavjee S. Update on donor assessment, resuscitation, and acceptance criteria, including novel techniques: non-heart-beating donor lung retrieval and ex vivo donor lung perfusion. Thorac Surg Clin. 2009;19:261-74. 
29. Schwartz DA. TLR4 and LPS hyporesponsiveness in humans. Int J Hyg Environ Health. 2002;205:221-7.

30. Endo T, Ogushi F, Kawano T, Sone S. Comparison of the regulations by Th2-type cytokines of the arachidonic-acid metabolic pathway in human alveolar macrophages and monocytes. Am J Respir Cell Mol Biol. 1998;19:300-7.

31. Maloney CG, Kutchera WA, Albertine KH, McIntyre TM, Prescott SM, Zimmerman GA. Inflammatory agonists induce cyclooxygenase type 2 expression by human neutrophils. J Immunol. 1998;160:1402-10.

32. Bingisser R, Stey C, Weller M, Groscurth P, Russi E, Frei K. Apoptosis in human alveolar macrophages is induced by endotoxin and is modulated by cytokines. Am J Respir Cell Mol Biol. 1996;15:64-70.

33. Wehrmann F, Lavelle JC, Collins CB, Tinega AN, Thurman JM, Burnham EL, et al $\gamma \delta$ T cells protect against LPS-induced lung injury. J Leukoc Biol. 2016;99:373-86.

34. McCulloh RJ, Spertus JA. Separating signal from noise: the challenge of identifying useful biomarkers in sepsis. Crit Care. 2014;18:121.

35. Guo YL, Huang H, Zeng DX, Zhao JP, Fang HJ, Lavoie JP. Interleukin (IL)-4 induces production of cytokine-induced neutrophil chemoattractants (CINCs) and intercellular adhesion molecule (ICAM)-1 in lungs of asthmatic rats. J Huazhong Univ Sci Technolog Med Sci. 2013;33:470-8.

Key Words: in vivo lung perfusion, acute lung injury, lung rehabilitation

\section{Discussion}

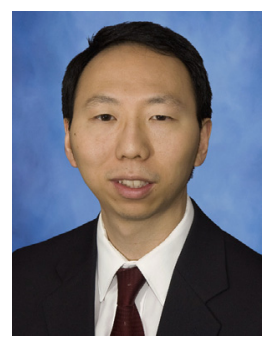

Dr J. Lin (Ann Arbor, Mich). Congratulation on an excellent presentation and an elegant study that really highlights the shift toward using lung perfusion as only an assessment tool to something that rehabilitates lungs. I do have a couple of questions for you.

How do differences in regional lung perfusion in the damaged lung affect the efficacy of the IVLP? It has been shown after aspiration that blood flow shifts away from the injured consolidated area. How does this affect the ability of the Steen solution and targeting agents to get to the injured portions of the lung? How does this affect the pulmonary pressures and flow to the less-injured portions, which are preferentially perfused? Is this why you used $8 \%$ cardiac output, while other studies use closer to 20\%? Would you give prostaglandin E1 like we do for lung donors? Would that help recruit the microcirculation in these areas, or would that be detrimental?

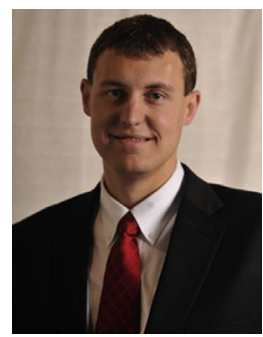

Dr J. Mehaffey (Charlottesville, Va). Excellent questions and excellent points. Thank you very much. PGE1 or some other pulmonary vascular relaxing agent would be very useful. The systemic injury model that we used with LPS provides a fairly heterogeneous injury; however, since perfusion is typically weighted toward the inferior lobes, we did see worse injury in the inferior lobes.

As to why we elected to use an $8 \%$ estimated cardiac output although the Toronto protocol for ex vivo lung perfusion uses $40 \%$, we had shown previously that modified strategies using maybe only $20 \%$ and APRV could reduce the lung injury. Also, since we were only perfusing one lung, the left lung is smaller, so we chose to use $8 \%$, slightly less than half the ideal $20 \%$ that we were shooting for.

I do think that differential circulation and perfusion of the lungs may end up being an issue in the long run. However, I think pressure monitoring is very crucial to this. As prescribed with ex vivo lung perfusion, a back-pressure of 1 to $5 \mathrm{mmHg}$ is critical.

Dr Lin. Also, the half-life of the LPS is several hours, so at only 2 hours, is the right lung still being injured by the LPS while the left lung has already been isolated from the injurious environment? How do these 2 points affect the results here?

Dr Mehaffey. I think that is an excellent question. This study is really a culmination of my time in the lab. The study that laid the groundwork for this study looked at different models of lung injury and sepsis-induced lung injury and found that this injury is very heterogeneous, and the animals respond differently. However, due to the complexity of the model and because this was a proof-of-concept study, we decided that we needed to start with a standardized approach. Looking at the data from our previous study, we saw that at 2 hours every animal had fallen below the threshold of a P/F ratio of 200 , indicating severe ARDS, and that was the reason for the 2hour cutoff.

I do think that the future direction for this project is a percutaneous approach, but what you said is very important. Most patients with severe ARDS have been in an ICU for days before being considered for ECMO therapy, and you would be intervening with this type of treatment approach. Further development of a long-term model is what we are currently working on, and I do think that this will be critical moving forward.

Nonetheless, IVLP does represent an excellent platform for drug or cell therapy delivery in the future.

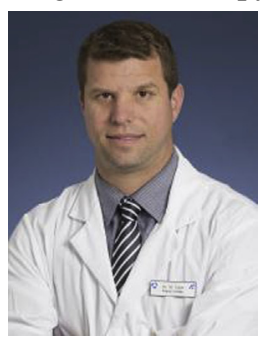

Dr M. Cypel (Toronto, Ontario, Can$a d a)$. Just to follow that and your answer, do you think there will be an advantage of really isolating the lung, because I assume you still get some systemic leakage, because you are not clamping the vessels, right?

Dr Mehaffey. Excellent question. We did look at this, and you are exactly right; there is some bleeding from the bronchioles into the IVLP circuit, as would be expected. However, we did confirm that there was no mixing from the IVLP circuit back into systemic circulation by measuring animal and circuit concentrations of albumin. The animal albumin remained below that of the IVLP circuit and actually decreased after the perfusion, indicating no mixing. I do think that that is a critical point, because there are certain therapies, whether cellular or pharmacologic, that would not be appropriate for systemic exposure, and you could deliver a very targeted therapy to rehabilitate these lungs. 


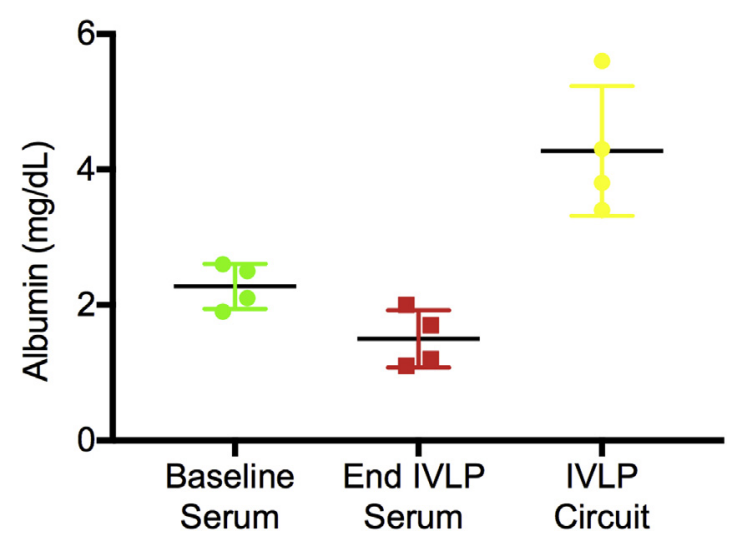

FIGURE E1. Serum albumin concentration at baseline and after IVLP perfusion, as well as in the IVLP circuit, showing a decreasing concentration after the initiation of IVLP despite a high concentration in the IVLP circuit. IVLP, In vivo lung perfusion.

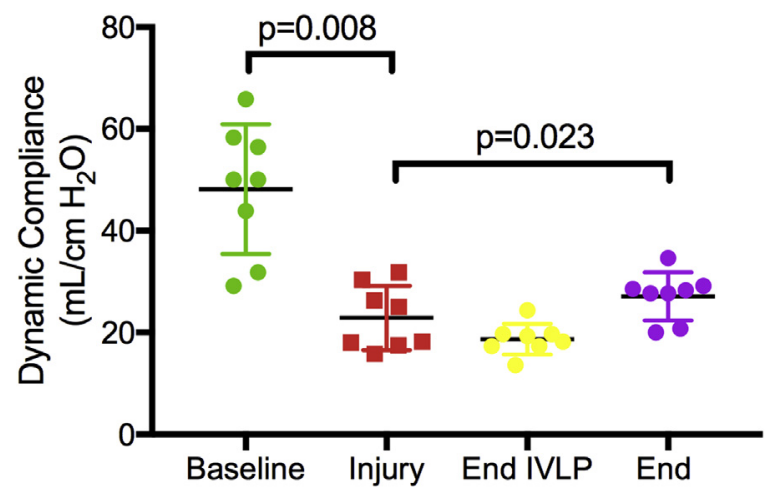

FIGURE E2. Comparison of right lung oxygenation and left lung oxygenation at baseline and at the end of the 2-hour injury period, showing no significant difference within the same animal. Dynamic lung compliance decreased significantly from baseline to 2 hours postinjury, followed by a significant increase from 2 hours postinjury to the cessation of reperfusion. $I V L P$, In vivo lung perfusion. 

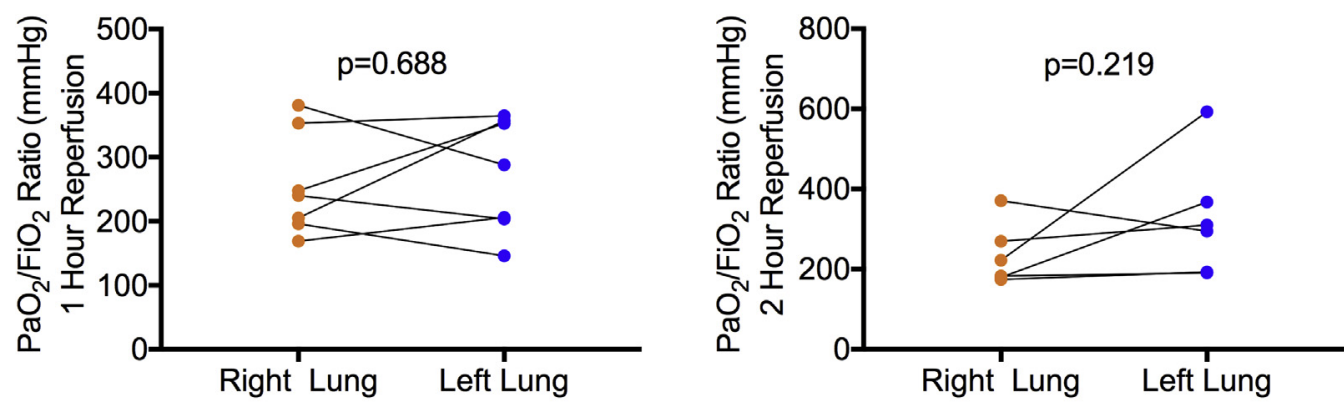

A

B
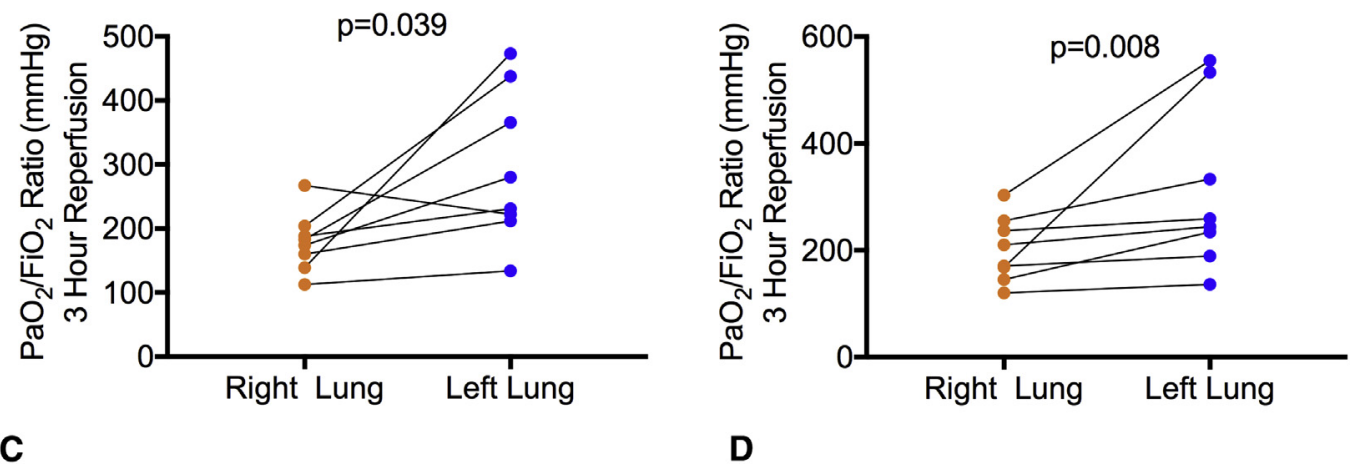

FIGURE E3. Right versus left lung oxygenation at 1 hour (A), 2 hours (B), 3 hours (C), and 4 hours (D) after reperfusion. $\mathrm{PaO}_{2}$, Partial pressure of oxygen in arterial blood; $\mathrm{FiO}_{2}$, fraction of inspired oxygen. 